\title{
Juntarse para alejarse y reproducir la clase. Estrategias residenciales de las clases medias en los márgenes asignados por el mercado. El caso de la población beneficiaria del plan PROCREAR en la ciudad de La Plata (2013-2015), Argentina.
}

Get together to get away and reproduce class. Residential strategies of the middle class, in the margins assigned by the market.The case of the population benefiting from the PROCREAR plan in the city of La Plata (2013-2015), Argentina.

\author{
Historial del artículo \\ Recibido: \\ 25 de septiembre de 2020 \\ Revisado \\ 17 de noviembre de 2020 \\ Aceptado: \\ 23 de noviembre de 2020
}

\author{
Violeta Ventura ${ }^{\mathrm{a}}$ \\ ${ }^{a}$ Consejo Nacional de Investigaciones Científicas y Técnicas (CONICET) / Universidad Nacional de La Plata (UNLP), La Plata, \\ Argentina. Correo electrónico: violetaventura.Ip@gmail.com
}

\section{Palabras clave}

Clases medias, contexto urbano, estrategia residencial, externalidad de vecindario, La Plata (Argentina).

\section{Keywords}

La Plata (Argentina), middle classes, neighborhood externality, residential strategy, urban context.

\begin{abstract}
Resumen
En los estudios urbanos latinoamericanos hay una vacancia respecto al rol de las clases medias en la producción de ciudad. También sobre el modo en que sus anclajes territoriales contribuyen a la construcción de la propia clase. En este artículo buscamos aportar a esa vacancia mediante el análisis de una estrategia residencial colectiva que, frente a los límites estructurales que les impuso el mercado de suelo, protagonizaron un grupo de beneficiarios/ as de un programa hipotecario para la vivienda destinado a las clases medias de Argentina. El caso de estudio en el que nos basamos es el de la ciudad de La Plata (2013-2015). Nuestros objetivos específicos son, (1) analizar las operaciones de distanciamiento y cercanía social que motorizaron dicha estrategia, deteniéndonos en cómo se pusieron en juego las externalidades de vecindad, y las percepciones en torno a la intervención estatal. (2) Reconstruir las búsquedas de terrenos y evaluaciones de distintas zonas de la ciudad realizadas por un subgrupo de beneficiarios/as, para analizarlas en relación con la dinámica urbana local. Para ello, adoptamos una perspectiva teórica pragmático-pragmatista, y consecuentemente un enfoque metodológico cualitativo sustentado en tres fuentes de datos: la observación de campo, las entrevistas en profundidad y la etnografía virtual. Nuestra principal conclusión es que dicha estrategia fue un proceso activo y recursivo de diferenciación social y espacial. Una operación de acercamiento social en la cual (ante su inminente suburbanización) integrantes de las clases medias platenses, buscando resguardar (y producir) su posición en el espacio social, reprodujeron una forma segmentada de residir en la ciudad.
\end{abstract}

\begin{abstract}
In Latin American urban studies, there is a vacancy regarding the role of the middle classes in the production of the city. Also, on the way in which those territorial anchorages affected the construction of the class itself. This article seeks to contribute to this vacation by analyzing the residential strategy carried out by beneficiaries of a mortgage program for housing for the Argentine middle classes (2012-2015). The case study on which we are based is that of the city of La Plata (2013-2015). Our specific objectives are, (1) to analyze the distancing and social closeness operations that drove this strategy, stopping on how the neighborhood externalities were put into play and the perceptions regarding the "fair" levels of intervention state. And (2) reconstruct the land searches and evaluations of different areas of the city carried out by a group of beneficiaries, to analyze them in relation to the local urban dynamics. For this, we adopt a pragmatic-pragmatist theoretical perspective and a qualitative methodological approach based on three data sources: field observation, in-depth interviews, and virtual ethnography. Our main conclusion is that strategy for an active process of social and spatial differentiation. An operation of social approach in the integral quality of the middle classes from La Plata - seeking to protect (and produce) their position in the social space - reproduced a segmented way of residing in the city.
\end{abstract}

Cómo citar: Ventura, V. (2020). Juntarse para alejarse y reproducir la clase. Estrategias residenciales de las clases medias en los márgenes asignados por el mercado. El caso de la población beneficiaria del plan PROCREAR en la ciudad de La Plata (2013-2015), Argentina. Investigaciones Geográficas, 60, 83-100. https:// doi.org/10.5354/0719-5370.2020.58679 


\section{Introducción}

A diferencia de la urbanización en los países centrales, "la ciudad latinoamericana" presenta características recurrentes nacidas de la estructura social del capitalismo dependiente y traducidas territorialmente por mercados de suelo desregulados (Jaramillo, 2008). A su vez, en Latinoamérica la dificultad estructural de la producción capitalista de vivienda se agrava, dando lugar a una mayor pluralidad de formas de producir y consumir el espacio residencial (Schteingart, 2001). Así, la promoción estatal y la producción capitalista del espacio encuentran un fuerte complemento en la construcción por encargo y la urbanización popular (Jaramillo, 2008), esta última es un factor estructural y estructurante de las ciudades y sociedades de la región.

No es casual, entonces, que los estudios urbanos latinoamericanos hayan realizado aportes medulares para comprender las "formas pobres de hacer ciudad" (Rodríguez, 2013). La exhaustividad de estos análisis muestra, por oposición, lo poco que sabemos respecto al lugar de las clases medias en procesos similares, uno de los mayores desafíos de la investigación sobre las ciudades latinoamericanas es visibilizar las diferentes formas de implicación de las clases medias en las disputas por las formas que asume la urbanización y por la distribución de sus efectos (Cosacov, 2014). Más aún, al abordar las clases medias no solo se ha minimizado la pregunta sobre los modos en que producen su anclaje territorial, sino también "el papel del espacio urbano en la producción diferenciada de esos anclajes y de experiencias sociales distintivas" (Cosacov, 2014, p. 32).

En este artículo nos sumamos a los esfuerzos de quienes aportaron a iluminar dicha zona gris para el caso argentino (Di Virgilio, 2007; Fava, 2014; Kessler \& Di Virgilio, 2008; Minujin, 1992; Svampa, 2005; y principalmente Cosacov, 2014, 2017), analizando la implementación del PROCREAR $^{1}$ (2012-2015) —un programa de créditos hipotecarios para la vivienda única destinado a las clases medias - en la ciudad de La Plata ${ }^{2}$. Más precisamente el modo en que dicho proceso fue modelado por las prácticas de su población beneficiaria, mediante las cuales estos/ as integrantes de las clases medias disputaron su lugar en la ciudad y con ello en la sociedad.

\section{EI PROCREAR y el caso platense: la innovación y sus límites}

Desde su lanzamiento en el año 2012 el PROCREAR se propuso un doble objetivo. El primero de ellos fue macroeconómico. Frente a la desaceleración de la economía nacional Argentina en 2011 y los efectos de la crisis internacional de 2008, surgió la necesidad de diseñar políticas de reactivación, la vivienda y la industria de la construcción eran un sector estratégico para ello. En materia habitacional se requería además que la política estuviera dirigida a un sector social con mayor sustentabilidad en la ecuación de recupero de los recursos. De allí que el entonces gobierno nacional buscó una salida keynesiana a la crisis, que a su vez fuera solidaria con las clases medias, un sector que en términos habitacionales había perdido el acceso a la hipoteca por las propias condiciones macroeconómicas. Su segundo objetivo, en el plano habitacional, fue entregar durante los cuatro años transcurridos entre 2012 y 2015, 400 mil créditos para la vivienda única, familiar y de ocupación permanente ${ }^{3}$.

El PROCREAR contó con dos modos de operar. Por un lado, construyó conjuntos habitacionales llamados "Desarrollos Urbanísticos" (DU) y, por el otro, movilizó recursos públicos mediante préstamos hipotecarios otorgados individualmente. La inversión pública, entonces, no solo financió y controló la producción de parte del parque habitacional por el lado de la oferta (DU), sino que además inyectó recursos para que determinados segmentos de demanda concurran al mercado y resuelvan la satisfacción de su necesidad habitacional.

\footnotetext{
${ }^{1}$ Programa de Crédito Argentino del Bicentenario para la Vivienda Única y Familiar.

${ }^{2}$ La Plata (659.575 habitantes) es una ciudad argentina de gran peso administrativo y político por ser capital de la provincia de Buenos Aires.

${ }^{3}$ Los/as destinatarios/as fueron aquellos/as ciudadanos/as argentinos/as o con residencia permanente en el país, de dieciocho a sesenta y cinco años, y que contaran con más de un año de antigüedad laboral. La población beneficiaria fue subsidiada por el gobierno nacional mediante tasas de interés inversas a su nivel de ingreso. Se trató de tasas fijas (entre $2 \%$ y $18 \%$ ) y bajas en comparación a los créditos otorgados por otros bancos. El capital era invariable y el plazo de pago de veinte o treinta años según el nivel de ingreso. En economías inflacionarias como la argentina, estas cualidades son especialmente convenientes para los/as tomadores/as de deuda, configurándose así el perfil social del Programa (Del Río, 2017).
} 
El programa inauguró así un nuevo ciclo de la política habitacional argentina ${ }^{4}$. En primer lugar, porque implicó el desplazamiento de una política destinada a subsidiar la oferta, a otra orientada predominantemente a subsidiar la demanda. En segundo lugar, porque redirigió recursos a los sectores medios ${ }^{5}$ restituyendo el papel del crédito hipotecario en la producción del espacio habitacional de la clase media (Del Río, 2017). Ello es importante considerando que en Argentina los sectores medios fueron perjudicados durante la primera década del milenio, dado que a pesar de la mejora en los indicadores socioeconómicos, hasta el lanzamiento del PROCREAR (2012) no contaron con políticas de financiamiento público orientado al acceso a la vivienda (Barenboim, 2019). Por ello, el PROCREAR fue una politica significativa, percibida por susbeneficiarios/as como una "oportunidad única” (Segura \& Cosacov, 2019).

A la luz de estos rasgos y trayectorias, el PROCREAR se constituyó en una política de carácter progresista que, por un lado, generó inclusión social mediante la creación de empleo y, por otro, promovió el acceso a la primera vivienda de un sector inquilinizado (Del Río, 2017). Sin embargo, el proceso de implementación local evidenció errores estratégicos en su diseño y consecuencias territoriales no deseadas.

En términos urbanísticos, el programa estuvo compuesto por distintas líneas: mientras que algunas de ellas supusieron interesantes innovaciones (Del Río, 2017), las más problemáticas reeditaron un viejo descuido de las políticas habitacionales argentinas: el suelo urbano. Dentro de este grupo se encuentra la modalidad "Compra de Terreno y Construcción" (CTC), la cual otorgó a los hogares financiamiento para la construcción de la vivienda y la compra del terreno donde esta se emplazaría. La decisión pública de subsidiar a la demanda en mercados de suelo desregulados potenció procesos especulativos y evidenció el error estratégico que significó su lanzamiento: cuantos más créditos se preadjudicaban, mayores eran los precios y la retención especulativa.

En distintas ciudades los/as beneficiarios/as de la modalidad CTC interpelaron a los gobiernos locales demandando una respuesta. En La Plata, se conformaron como un colectivo de alrededor de 2.000 personas que, en tan solo un mes, logró la sanción de una normativa urbana: la ordenanza $\mathrm{N}^{\circ} 11.094 / 13^{6}$. Esta habilitó al poder ejecutivo municipal a desafectar parcelas ubicadas en zonas de uso rural intensivo y de reserva urbana, y reasignarles (con destino exclusivo al PROCREAR) un nuevo indicador urbanístico denominado "zona residencial de promoción" (U/R3) el cual habilita la construcción de viviendas residenciales ${ }^{7}$. Lograron también la incorporación en su decreto reglamentario de una modalidad específica de implementación —conocida nativamente como "Vía 2"la cual permitió que los/as beneficiarios/as conformaran subgrupos según sus propios criterios, relevaran fracciones de tierra rural, entablaran negociaciones con los/as dueños/ as y, finalmente, autogestionaran los trámites y obras requeridas para su rezonificación y subdivisión. De los 1.550 lotes urbanos que se generaron en la ciudad para canalizar la implementación del PROCREAR, 1.240 agrupados en once barrios - nacieron de esta estrategia colectiva impulsada por beneficiarios/as.

\section{Objetivos del artículo}

El presente artículo parte, entonces, de una particularidad: en la capital de la provincia de Buenos Aires, la implementación de una política de escala como el PROCREAR fue canalizada

\footnotetext{
${ }^{4}$ También, respecto a la trayectoria de la política hipotecaria, la cual tiene en Argentina una historia de tropiezos y discontinuidades. En los años 90 el Banco Hipotecario de la República Argentina — hasta ese entonces de gestión y propiedad nacional— sufrió una fuerte reestructuración (1989-1993). En este período cerró más de la mitad de sus sucursales y redujo significativamente su actividad como otorgante de préstamos hipotecarios residenciales (Scatolini, 2014). Finalmente, en 1997 la entidad fue privatizada. A su vez, junto a la reestructuración y privatización del Banco Hipotecario, el Banco Central flexibilizó la regulación del crédito. Ello derivó en una reorientación del crédito hipotecario priorizando la maximización de la fórmula de recupero y la apuesta a transformar los préstamos en títulos valores (Cravino, Fernández Wagner \& Varela, 2002). El Estado perdió así una herramienta nodal para regular el mercado hipotecario, lo cual habilitó — en un contexto de aumento de la pobreza estructural y por ingresos - un redireccionamiento de los créditos hipotecarios hacia los sectores de mayores ingresos (Del Río, 2017). En este marco, la relativa desmercantilización de las tasas hipotecarias del PROCREAR, además de favorecer el acceso a la vivienda a una población de inquilinos/as, restituyó "el papel que juega el crédito hipotecario en la producción del espacio habitacional de la clase media" (Del Río, 2017, p. 265).

${ }^{5}$ Diferenciándose del extremo de mayores ingresos de la población, los/as beneficiarios/as del PROCREAR que analizamos contaban con un tope de ingresos máximos para poder acceder al crédito. A su vez los beneficios del Programa no alcanzaban a la población que fuera propietaria de otros inmuebles. Tampoco podían acceder al crédito los sectores de menores ingresos, ya que por un lado se debía contar con ciertas condiciones de empleo formal y con dinero para abordar gastos extras de la construcción y la compra del lote. A la luz de esas condiciones el PROCREAR fue presentado públicamente y desde su lanzamiento como una política destinada a las clases medias.

${ }^{6}$ Recuperado de https://www.concejodeliberante.laplata.gob.ar/digesto/or11500/or11094.asp?ver=1\&resol=1024x768

${ }^{7}$ Cuando hagamos referencia a este proceso lo denominaremos "rezonificación".
} 
y modelada a través de una normativa coproducida entre la población beneficiaria - perteneciente a las clases medias - y el gobierno municipal. Mediante ella el municipio limitó su rol a la intermediación — resolviéndose el conflicto mediante el imperio del mercado-y promovió la apertura indiscriminada del perímetro urbano, para reforzar una configuración urbana extensa y difusa con los consabidos costos ambientales, sociales y económicos que ello implica. Mientras tanto, los/as beneficiarios/as lograron su principal objetivo: elegir la localización de los predios a ser rezonificados por el Estado y la composición del vecindario.

Partiendo de ese punto, el objetivo del artículo es analizar cómo integrantes de las clases medias ${ }^{8}$ maniobraron frente a la tensión entre la oportunidad residencial (Di Virgilio, 2007) que les brindó el Estado (PROCREAR) y la posición devaluada en la estructura urbana - disonante con sus expectativas residenciales - que tendencialmente les asignó el mercado de suelo. Buscamos con ello acceder al modo en que esta población perteneciente a las clases medias, constreñida por el mercado, financiada por el Estado y orientada por sus esquemas de preferencia, produjo ciudad.

Para ello, nuestros objetivos específicos son dos. El primero, analizar las operaciones de distanciamiento y cercanía social que motorizaron su estrategia residencial colectiva - "Vía 2"- deteniéndonos en la forma en que se pusieron en juego las externalidades de vecindad (Abramo, 2009) y las percepciones en torno a los niveles "justos" de intervención estatal. El segundo, reconstruir las búsquedas de terrenos realizadas por un subgrupo de beneficiarios/ as — una vez conquistada la normativa — en búsqueda de aplicar a la "Vía 2". En este punto indagaremos qué variables buscaron evitar y cuáles valoraron positivamente al incorporarse al mercado de localizaciones intraurbanas (Del Río, 2012) a fin de analizarlas bajo la luz de la dinámica urbana local.

Tal como afirma Cosacov (2017), el espacio urbano es un orden negociado, resultado de actores con desiguales capacidades de incidir en su estructuración. Las estrategias residenciales de las (poco estudiadas) clases medias son parte de esas negociaciones. Son también una forma de resguardar y producir su posición de clase mediante la disputa de sus anclajes territoriales. Tal como afirma Segura (2015), ante la constatación de un acceso desigual a los bienes, servicios y oportunidades urbanas, es necesario preguntarse por "las dinámicas sociales que (re) producen este orden, así como por los modos en que los actores sociales experimentan dicha desigualdad" (p. 128).

\section{Andamiaje analítico}

Para dar cuenta de cómo las clases son vectores que transforman los territorios, al mismo tiempo que los territorios son vectores de potencial integración y/o segmentación de estas (Di Virgilio \& Heredia, 2012) tomaremos aportes bibliográficos provenientes de la sociología y la geografía urbana. En lo que sigue puntualizaremos en aquellas categorías analíticas que nos permitieron abordar empíricamente la relación entre las clases medias y la producción del espacio urbano, en el marco de la implementación local de una política pública nacional (PROCREAR).

La bibliografía sobre movilidad residencial aportó algunas de estas herramientas, convirtiéndose en un lente privilegiado para analizar tanto los procesos de modificación y/o reproducción de las dinámicas urbanas (Abramo, 2009; Duhau, 2003; Smolka, 1992) como la forma en que la experiencia de la clase es producida y reproducida en los modos de habitar (Cosacov, Di Virgilio \& Najman, 2018). En nuestro caso, en las expectativas en torno a futuras formas de habitar y las disputas para materializarlas.

En los estudios urbanos argentinos, fue Di Virgilio quien introdujo el problema de la movilidad residencial centrando su mirada en la relación entre espacio urbano y estratificación social (Ramírez, 2016). Desde su perspectiva, el modo en que las personas se mueven dentro del espacio residencial intraurbano se define en la intersección entre (1) las oportunidades habitacionales, (2) las necesidades y expectativas residenciales de los hogares y (3) los factores estructurales que habilitan o limitan la acción. Es sobre la interacción entre los últimos dos puntos, que permite indagar la disputa por la "Vía 2" llevada adelante por los/as beneficiarios/as platenses del PROCREAR. Otro antecedente que tomamos son los trabajos de Delaunay \& Dureau (2004), quienes distinguen cuatro componentes

\footnotetext{
${ }^{8}$ Las ciencias sociales latinoamericanas han avanzado en un difícil debate respecto a la categoría "clases medias", identificando en ese camino problemas a) conceptuales para definirlas, b) falta de trabajos empíricos sobre el sector y b) usos morales de la categoría al interior de las propias discusiones académicas (Adamovsky, 2013; Garguin, 2006). Sin desconocer ese debate y tratando de aportar al segundo aspecto utilizaremos la categoría "clases medias" por ser ese uno clivaje de autoadscripción identitaria de la población estudiada. Seguimos con ello el planteo de Garguin para quien el uso de dicha categoría tiene sentido siempre que se trate de un proceso de auto adscripción, pensando en las categorías morales articuladas al propio enclasamiento a fin de distinguirse identitariamente de otros grupos o bien analizarla como una categoría atribuida/ construida externamente como proyecto político, social, moderno, progresista, conservador, etc.
} 
de la movilidad residencial: la vivienda, el tipo de tenencia, la localización y la autonomía residencial del individuo. A través de ellos intentan "confrontar las historias biográficas individuales y la historia estructural de la ciudad. Las sincronías de una y otra describen con instructiva precisión, los determinantes contextuales de la movilidad residencial" (Delaunay \& Dureau, 2004 citados en Ramírez, 2016, p. 26).

Tomando estos dos aportes veremos cómo las mudanzas de estos/as beneficiarios/as estuvieron motivadas por una oportunidad residencial —el PROCREAR_que implicó un cambio del tipo de tenencia de la vivienda y, a la par, una devaluación en su localización en la ciudad. Frente a los condicionantes impuestos por la estructura urbana y el mercado de suelo, la "Vía 2" será entendida como una estrategia que buscó ganar márgenes de maniobra a fin de dar lugar a las necesidades y expectativas de beneficiarios/ as. Es por ello que, la noción de estrategia residencial entendida como "maniobras, modos en que los hogares negocian su inscripción en la ciudad" (Cosacov, 2014, p. 42) — será importante para observar la capacidad de agencia de los hogares frente a la estructura que los condiciona, contribuyendo a su vez a configurar los procesos de diferenciación social y espacial (Di Virgilio \& Heredia, 2012).

Para pensar dichas estrategias, un concepto clave será el de localización, entendida como un rango de orden que vincula al espacio social con el físico (Bourdieu, 2013). La biografía ha mostrado exhaustivamente como sociedades fuertemente estratificadas como las latinoamericanas se caracterizan por una división social del espacio (Duhau, 2003) sostenida en una triple jerarquización: la territorial, la económica y la simbólica (Cosacov, 2014). Lo mismo sucede con el espacio residencial: vivir en un lugar $u$ otro de la ciudad tiene efectos estructurantes en la vida de las personas y, por ello, moverse en su interior es una decisión crucial (Abramo, 2009) que implica potenciales pérdidas y ganancias de localización (Bourdieu, 2013).

En igual sentido, Abramo (2003) sostuvo que el lugar de residencia de los hogares y su ubicación relativa respecto a las externalidades y jerarquías urbanas se constituye en un capital locacional, el cual lejos de ser estable, se devalúa y valoriza con el paso del tiempo y bajo determinadas condiciones. Ahora bien, como adelantamos, las distintas localizaciones en la ciudad no implican solo un acceso diferencial a bienes y servicios urbanos. Además, "la proximidad en el espacio físico permite que la proximidad en el espacio social produzca todos sus efectos facilitando o favoreciendo la acumulación de capital social" (Bourdieu, 2013, p. 122). Continuando esta reflexión, Abramo (2009) sostiene que, cada vez más, en las segmentadas ciudades latinoamericanas, las decisiones locacionales se definirán por las "externalidades de vecindad", es decir, por la búsqueda de ganancias provenientes de la interacción con hogares de igual o mayor nivel de ingreso y la aversión a elegir barrios donde residen hogares con menor nivel de ingreso. El espacio residencial se configura así más por la posición relativa de los hogares pertenecientes a distintos niveles socioeconómicos, que por aspectos tales como las distancias a los centros y subcentros o la dotación de servicios (Abramo, 2009).

Antes de seguir debemos hacer una mención respecto a uno de los condicionantes estructurales sobre los que los/as beneficiarios/as del PROCREAR trazaron sus estrategias residenciales: la estructuración del espacio residencial y la distribución desigual de los distintos estratos socioeconómicos en él. Levy (1998) aporta tres conceptos que nos permitieron pensar el vínculo entre la movilidad residencial de los/as beneficiarios/as y su apropiación del espacio urbano. El primero es el de tipo residencial, definido como la relación entre las características del parque inmobiliario y las características socioeconómicas y sociodemográficas de su población. El segundo, el de espacio residencial, entendido como la agregación de los diferentes tipos residenciales conformados en la ciudad y, por lo tanto, como una estructuración sociodemográfica del parque habitacional (Del Río, 2012). Finalmente, la posición residencial remite a la posición de un grupo o individuo en el espacio residencial, la cual está dada por el tipo residencial al que pertenece. Vinculado a lo anterior, Duhau \& Giglia (2004) aseguran que las metrópolis latinoamericanas no están conformadas por una periferia, sino por múltiples periferias, las cuales adoptan la forma de contextos urbanos específicos. Es decir, formaciones espaciales que se diferencian por aspectos tales como las modalidades de organización del espacio urbano, los usos del espacio público y privado y los conflictos dominantes respecto al espacio. Como ya adelantamos, analizar qué tipos residenciales y contextos urbanos ponderaron los/as beneficiarios/as - por sobre otros que se encontraban en el mismo rango de mercado - y de cuáles buscaron diferenciarse simbólica y territorialmente, será parte del objetivo de este artículo.

\section{Materiales y métodos}

El objetivo de este artículo requiere de una perspectiva teórica pragmática-pragmatista (Cefai, 2012) que exige, a su vez, un enfoque metodológico cualitativo y denso a fin de reconstruir las prácticas e interacciones puestas en juego en la estrategia residencial de la población 
beneficiaria, reencontrarles sentido y conocer el modo en que operaron en la producción de ciudad.

Respecto a nuestro abordaje empírico, usamos distintas técnicas y fuentes. Por un lado, se realizaron observaciones de campo. Las primeras once observaciones se realizaron durante las negociaciones y sanción de la ordenanza $\mathrm{N}^{\circ} 11.094 / 13$. Las segundas diez se realizaron una vez sancionada la citada normativa. Dentro de este grupo fueron de especial utilidad aquellas en las que acompañamos a un subgrupo de beneficiarios/as a recorrer predios susceptibles de transformarse en futuros barrios bajo los efectos de la ordenanza $\mathrm{N}^{\circ} 11.094 / 13$, lo cual nos permito acceder a sus evaluaciones de las distintas zonas de la ciudad. Por último, un tercer tipo de observaciones (cinco de ellas) se realizaron en los actos públicos encabezados por funcionarios del programa o el municipio.

Una segunda fuente de información en la que se basa esta investigación son dieciocho entrevistas en profundidad realizadas a beneficiarios/as del PROCREAR. Algunas de ellas fueron realizadas entre finales de 2013 e inicios de 2014 y se centraron en el proceso de sanción de la ordenanza $\mathrm{N}^{\circ} 11.094 / 13$. Otras entre los años 2014 y 2016 e indagaron, además, en el proceso de implementación de la normativa. En los dos casos se empleó un guion semiestructurado y el muestreo fue intencional. En el primer grupo, se garantizó contar con las perspectivas tanto de quienes tuvieron una participación activa en la organización colectiva y en la redacción de la ordenanza $\mathrm{N}^{\circ} 11.094 / 13$, como de aquellos/as beneficiarios/as free rider $^{9}$ (Olson, 1992). En cuanto al segundo grupo, se priorizó entrevistar a integrantes de los distintos barrios generados por la "Vía 2" de la ordenanza No 11.094/13.

Finalmente, el principal insumo fue una etnografía virtual (Hine, 2004) en la que analizamos las interacciones generadas en dos grupos de Facebook (FB): el "Grupo Unificado PRO.CRE.AR LA PLATA Terreno + Construcción" (GULP) y el grupo "22 de octubre". El primero de ellos es un grupo de FB abierto (6.874 miembros) en torno al cual los/as beneficiarios/as platenses del PROCREAR se organizaron colectivamente y presionaron por la sanción de la ordenanza $\mathrm{N}^{\circ}$ 11.094/13 y la "Vía 2". A los fines de esta investigación, esta fuente nos permitió reconstruir las estrategias por ellos/as trazadas, así como sus percepciones en torno a la estatalidad, la ciudad y el vecinazgo. El segundo grupo que analizamos tuvo una dinámica distinta: se trata de un grupo de FB cerrado en el que catorce beneficiarios/as del PROCREAR se organizaron a fin de visitar y evaluar ofertas de macizos rurales indivisos susceptibles a ser rezonificados mediante la "Vía 2" de la ordenanza $N^{\circ} 11.094 / 13$. Este grupo, en complementación con las observaciones de campo, nos permitió conocer en mayor profundidad sus evaluaciones y expectativas en torno a las distintas zonas de la ciudad.

El tipo de fuentes exige dedicar unas breves consideraciones. Es evidente que la introducción de las tecnologías de la información y la comunicación (TIC) en la vida cotidiana produjo profundas transformaciones en la vida social. Aún más lo hizo la masividad de las interacciones virtuales habilitadas por el surgimiento de internet $2.0^{10}$. Con ello, las ciencias sociales se encontraron ante un desafío doble: conceptual y metodológico (Hine, 2004; Mosquera Villegas, 2008; Welschinger Lascano, 2012).

De un lado, la vertiginosidad con la que crecieron las interacciones virtuales y la imbricación entre las dinámicas online y offline, hicieron que la investigación cualitativa tenga que replantearse aspectos centrales como son las lógicas de circulación y conformación de los consensos, las dinámicas de los conflictos, la forma en que se implican los distintos actores, los tiempos con que se producen las interacciones, sus visiones del territorio y la circulación por él, etc. Dicho de otro modo, en términos analíticos la interactividad y rapidez que habilita —en nuestro casoFacebook, hacen que las interacciones online respondan a lógicas distintas, aunque no escindidas, de las offline. A su vez, las técnicas de investigación se tensionaron ante estos nuevos desafíos. Uno de ellos es el caudal de información que circula en las redes, lo cual dificulta el análisis y también su gestión operativa. El último punto nos demandó tomar decisiones respecto a cómo descargar, guardar y sistematizar la información disponible. Decidimos trabajar con toda la información publicada en los perfiles seleccionados, es decir, no filtramos datos en su descarga ni recurrimos a criterios cuantitativos para determinar la relevancia de la información publicada en FB. Por el contrario - sin descuidar las concurrencias o actividad de cada posteo - dimos continuidad al enfoque cualitativo, haciendo lecturas y relecturas del material centrando la

\footnotetext{
${ }^{9}$ La expresión inglesa free rider remite a quienes viajan en el transporte público sin abonar su pasaje; lo que en español llamamos "polizones". Olson (1992) trabajando sobre la acción colectiva, refiere con dicho término a quienes en el marco de controversias sociales se benefician del trabajo colectivo realizado por otros/as, accediendo con un esfuerzo menor a los mismos beneficios.

${ }^{10} \mathrm{El}$ salto de calidad de la internet 2.0 es que, mediante ella, los/as usuarios/as pueden ser receptores/as y también emisores/as de información habilitándose así la interacción simultánea (Aguirre Sala, 2013, p. 130).
} 
atención en las interacciones que en estos muros se daban y en sus productividades jurídicas, sociales y territoriales (Melé, 2016).

\section{Resultados}

El PROCREAR fue una política novedosa respecto a la trayectoria del crédito hipotecario vinculado a la vivienda en Argentina. Con él, los sectores medios volvieron a aparecer en la agenda estatal (Barenboim, 2019) siendo percibido por los/as beneficiarios/as como una oportunidad única (Segura \& Cosacov, 2019). Para comprender la forma en que las personas se mueven dentro del espacio residencial intraurbano, además de las oportunidades residenciales debemos considerar los límites que impone la estructura urbana y las necesidades, recursos y expectativas de los hogares (Di Virgilio, 2007). Los/as beneficiarios/as del PROCREAR se encontraron con dos límites estructurales: la escasez y desregulación del mercado de suelo y la valorización diferencial de los bienes urbanos respecto a su salario (Del Río \& González, 2014). Ello los/as forzó a jugar en un segmento de bajos precios, asignándoles en el mercado una posición devaluada en la estructura urbana, la cual resultó "disonante" respecto a sus trayectorias y expectativas urbanas (Ventura, 2020). A pesar de ello, decidieron seguir adelante proyectando sus mudanzas, siendo la disputa ${ }^{11}$ por la "Vía 2" su principal estrategia para neutralizar la pérdida de capital locacional (Abramo, 2003).

En primer lugar, para los/as beneficiarios/as la "Vía 2" era importante porque reducía sus márgenes de incertidumbre ya que "el Estado intervenía, pero hasta ahí"12. Una fuerte intervención estatal representaba para ellos/as dos desventajas. La primera se vinculaba a su poder de pago el cual-aunque escaso- dejaría de operar como un resguardo ante su inminente suburbanización. Así, en el marco de las negociaciones por contenido de la ordenanza $\mathrm{N}^{\circ} 11.094 / 13$, el municipio propuso una modalidad llamada "Vía 1"13. En términos urbanísticos esta modalidad daba un protagonismo mayor a los criterios técnicos al momento de definir cuáles serían los predios rezonificados por la nueva normativa. Complementariamente tanto el vínculo entre la oferta y la demanda, como las obras de infraestructura necesarias para urbanizar dichos predios eran gestionados por el municipio de La Plata. La llamada "Vía 1" no prosperó en la ciudad, en parte, por la falta de interés de los/as beneficiarios/as quienes al describir sus desventajas señalaban que, por el mecanismo de calificación y evaluación de los predios propuesto por el municipio, los primeros lotes rezonificados serían aquellos "más baratos" y, por tanto, de menor tamaño que los que ellos/as (suponían) podrían pagar. Se ubicarían, además, en zonas "menos cotizadas" de la ciudad. Solo cuando todos los lotes del predio rezonificado por la "Vía 1" fuesen asignados, se procedería a la rezonificación de un nuevo predio de mayor valor y "de mejores condiciones". En sus palabras: "si uno tiene la capacidad de afrontar un lote de mayores dimensiones o valor, deberá esperar que estén disponibles"14.

La segunda desventaja que encontraban en una fuerte intervención estatal era que, en sus imaginarios, si el Estado intervenía en la producción de suelo urbano les asignaría posiciones devaluadas en la estructura urbana. Durante la negociación por la "Vía 2", dice un entrevistado, había un "clamor popular" pidiendo que "nos dejen elegir a nosotros las tierras y no nos manden a un lugar cualquiera" 15. Al indagar en ello encontramos que la cuestión de una localización más o menos central, consolidada y accesible, no parecía ser una variable especialmente ponderada ${ }^{16}$. Al contrario, los predios elegidos y negociados para generar sus futuros barrios - siempre dentro de sus posibilidades de pago - se inscribieron en entornos rurales dedicados a la producción ganadera, el cultivo extensivo y/o la actividad fruti-hortícola (figura 1).

Un lugar cualquiera era, en cambio, un lugar considerado "peligroso": incidir en la localización, dice otro entrevistado, era importante "no en relación a una cuestión " $x$ " de la ubicación, sino que la inseguridad era el problema"17. Es

\footnotetext{
${ }^{11}$ Nos referimos a una disputa porque en una primera instancia el gobierno municipal se opuso a dicha iniciativa, dando lugar a un arduo proceso de negociación en torno a ella (Ventura, 2020).

${ }^{12}$ La cita corresponde a una entrevista realizada a una beneficiaria del PROCREAR en enero de 2014. Mediante la ordenanza $\mathrm{N}^{\circ}$ 11.094/13 el municipio se limitó a ocupar un rol de facilitador frente a la propuesta realizada por beneficiarios/as, siendo la "Vía 2" un contrato entre privados.

${ }^{13}$ Esta modalidad de implementación nunca fue implementada en la ciudad. No es interés de este artículo profundizar en ello.

${ }^{14}$ Fragmento de documento interno de los/as beneficiarios/as, publicado en el muro de Facebook GULP.

${ }^{15}$ La cita corresponde a una entrevista realizada a Aldo, beneficiario del PROCREAR, en febrero de 2014.

${ }^{16}$ En ninguna de nuestras fuentes la pérdida de centralidad e infraestructura apareció como un problema relevante. Incluso, en muy pocas ocasiones la problemática fue mencionada.

${ }^{17}$ La cita corresponde a una entrevista realizada a Nicolás, beneficiario del PROCREAR, en junio de 2014.
} 


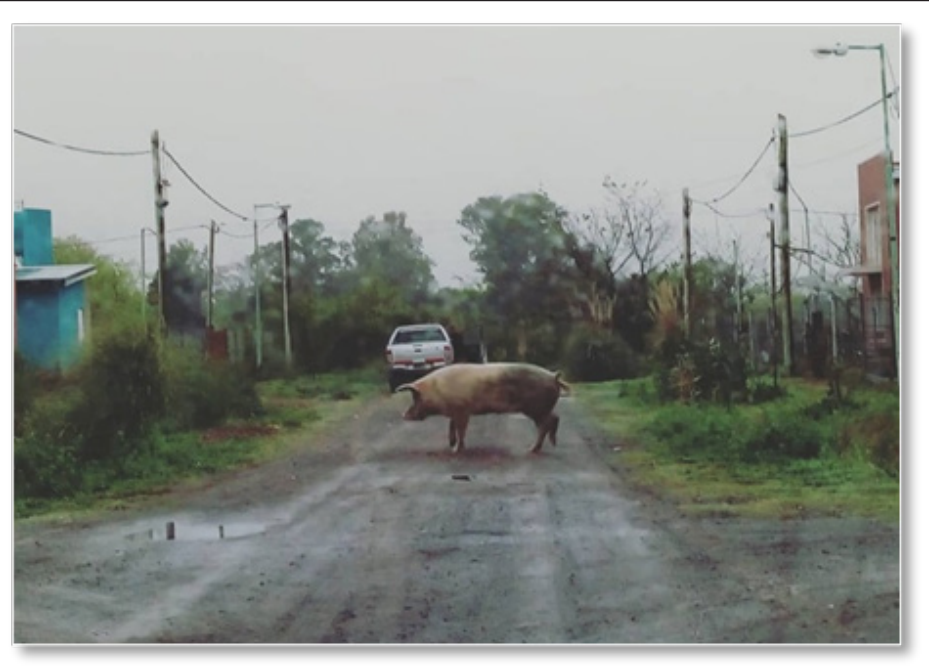

Figura 1. Barrio generado mediante la "Vía 2". Fuente: foto cedida por una beneficiaria del PROCREAR, septiembre de 2019.

sabido que el temor y los relatos en torno a la peligrosidad son un principio urbanístico, constituyéndose la geografía del miedo ${ }^{18}$ en un proceso activo en la producción del espacio urbano (Carrión Mena \& Núñez-Vega, 2006). Ahora bien, independientemente de la instrumentalización (y producción) económica del temor, su particular componente psicológico hace que, una vez que estos imaginarios se echan a andar, operen sistemáticamente en las decisiones individuales de los/as usuarios/as de la ciudad. Si bien para algunos/as de nuestros/as entrevistados/as el peligro se asociaba a lugares ubicados en "las afueras de la ciudad", la mayoría de los loteos generados por la "Vía 2" se ubicaron allí. Esto es así porque, lo que volvía seguro a un territorio era "la sapienza de quiénes van a conformar el futuro barrio"19, siendo constantes las apelaciones a que podrían confiar en sus nuevos/as vecinos/as y estar seguros/as junto a ellos/as, aun sin conocerlos/as con anterioridad.

De este modo, además de evitar que el Estado les asigne una posición en la ciudad, era importante en su estrategia residencial garantizar la posibilidad de realizar mudanzas conjuntas guiadas por la afinidad de clase. Al respecto encontramos que, en parte, incidir en la composición del loteo fue importante por las interacciones que este acto habilitaba. En trabajos precedentes (Ventura, 2020) vimos cómo la capacidad de los/as beneficiarios/as para dar forma a la normativa urbana respondió a un imponente despliegue de capital social y cultural. Fue ese mismo capital el que generó expectativas respecto a las futuras geografías de oportunidades de los hogares (Del Río, 2012): “con futuros vecinos así, no hay nada que sea imposible!"20. La percepción de esta beneficiaria se cumplió, siendo nodal durante todo el proceso la presencia de vecinos/as capitalizados/as cultural y socialmente: hubo abogados/ as que asesoraron a los/as demás en su relación con el Banco Hipotecario y con los/as dueños/as de los predios; ingenieros/as coordinando la realización de obras de infraestructura; paisajistas proyectando la forestación de los nuevos barrios; arquitectos/as organizando compras colectivas de materiales y colaborando el diseño de las viviendas; comunicadores/as pensando estrategias de interpelación pública; artistas difundiendo la problemática; etc. En síntesis, en diversas situaciones, los/as beneficiarios/ as confluyeron trabajando gratis para futuros/as vecinos/ as, lo cual hizo más confiable, fácil y económica la urbanización de sus barrios.

Por otra parte, la autogestión en la composición del vecindario generó expectativas en torno a las formas de habitar los futuros barrios. Así, pocos días después de la sanción de la ordenanza, Dolores en el muro de Facebook del GULP dedicó un poema a sus futuros/as vecinos/as:

\footnotetext{
${ }^{18} \mathrm{La}$ cual es independiente de los procesos empíricos del delito y la violencia urbana.

${ }^{19}$ Fragmento extraído de un documento oficial generado por el colectivo de beneficiarios/as.

${ }^{20}$ Publicado el 20 de noviembre de 2013 en el muro de Facebook del GULP.
} 
Hay gente que con solo dar la mano / Rompe la soledad, pone la mesa / Sirve el puchero, coloca las guirnaldas/ Que con solo empuñar una guitarra / Hace una sinfonía de entrecasa ... Y se queda después, como si nada / Y uno se va de novio con la vida / Desterrando una muerte solitaria / Pues sabe que a la vuelta de la esquina / Hay gente que es así, tan necesaria. (Comunicación personal, diciembre 23, 2013).

Esta publicación generó numerosas respuestas inmediatas y afectivas en las cuales el "tipo de gente" — la afinidad de clase - con quienes se proyectaba la mudanza, aparecía como un incentivo central para la "Vía 2" "21; en palabras de Marta como "un sueño que engrandece el deseo de la casa propia, porque el barrio también es parte del hogar". De igual modo, Ana celebró la composición de los futuros barrios, adquiriendo los/as vecinos/as un estatus lugar físico: "Yo también quiero vecinos así, vecinos donde criar a mis hijos"22.

Por último, promoviendo mudanzas conjuntas, los/as beneficiarios/as jerarquizaban el retorno a una dinámica barrial idealizada:

¡Vamos gente! volvamos a nuestra esencia. Charlas en las veredas, iiivecinos que son amigos, que te llevan al hospital en una urgencia y te invitan a tomar mate en el invierno!!! No tenemos que perder esta energía que se está formando. (Comunicación personal, diciembre 23, 2013).

Así, gestionando el vecindario desde lazos de confianza, proyectaban el retorno a barrios habitados e identitarios.

\section{Buscar una periferia dentro de las periferias}

Hasta acá vimos que parte de la estrategia residencial de los/as beneficiarios/as fue modelar el contenido de la normativa urbana (ordenanza $\mathrm{N}^{\circ} 11.094 / 13$ ) a fin de incidir en la composición del vecindario y limitar la intervención estatal, en particular la asignación de una localización por parte del Estado. En lo que sigue mostraremos - una vez conquistada la normativa - la territorialización de sus esquemas de preferencia locacional, así como las formas en que durante sus búsquedas de terrenos gestionaron distancias y cercanías sociales. Ello nos permite reponer cómo la desigual apropiación del espacio residencial y urbano se reproduce también mediante las — poco estudiadas - prácticas de las clases medias.

En particular, analizaremos la búsqueda de terrenos de un subgrupo de beneficiarios/as y la relación entre el tipo de periferias urbanas que eligieron y la dinámica urbana local. Ello nos permitirá mostrar cómo la estructura urbana prefiguró sus elecciones residenciales, al mismo tiempo que estas reprodujeron modos desiguales de producir y consumir ciudad.

El primer terreno que visitó este grupo se ubicaba en Gorina — norte de la periferia platense- - una delegación que vivió profundas transformaciones durante las últimas tres décadas, conviviendo allí migrantes internos que en 1980 accedieron al suelo mediante tomas ilegales de tierras, con urbanizaciones cerradas destinadas a sectores altos. A partir de los 2000, hubo una retracción de la actividad hortícola y la localidad atrajo cada vez más a sectores medios y medios-altos. El contexto urbano de esta primera búsqueda, entonces, se conforma por un perfil residencial de viviendas de fin de semana, grandes intersticios vacantes, barrios populares y una dinámica de crecimiento en la que los sectores medios tiene cada vez más protagonismo. Si bien la cercanía de viviendas precarias y la vacancia del lote lindero generaron preocupación entre beneficiarios/as, el temor se disipó al constatar que en los alrededores había una gran cantidad de "casas nuevas en construcción”. Finalmente, concluyeron que Gorina era un lugar indicado para construir sus casas por ser una "zona en evolución, pero muy buena para hacer la movida"23.

En el eje norte de la ciudad visitaron además otros dos predios, uno de ellos ubicado en el barrio El Rincón y otro en Arturo Seguí. El Rincón es un típico loteo generado en la Argentina entre los años 1940-1970, cuando la regulación urbanística exigía escasos costos para la subdivisión del suelo a las empresas loteadoras. En sus primeras décadas pocas parcelas se edificaron efectivamente, quedando buena parte del loteo ocioso por décadas. Esto se combinó con el allegamiento de sectores populares y poseedores de la tierra, dando lugar a un vecindario heterogéneo. En las últimas dos décadas (2000-2020), la relativa saturación de las áreas urbanas consolidadas del eje norte contribuyó a su valorización inmobiliaria, lo que promovió la ocupación residencial por parte de sectores medios. Arturo Seguí también es

\footnotetext{
${ }^{21}$ Para un mayor desarrollo de este punto ver Ventura (2020).

${ }^{22}$ Las citas del párrafo corresponden a una publicación realizada el 23 de diciembre de 2013 en el muro de Facebook del GULP.

${ }^{23}$ Los fragmentos citados en este párrafo fueron publicados el 30 de octubre de 2013 en el muro de Facebook del grupo "22 de octubre".
} 
una zona recientemente valorizada en el marco de las tendencias de suburbanización del eje norte de La Plata. En términos sociales, la composición del vecindario es heterogénea, ya que hay en el plano residencial desde casas de fin de semana hasta asentamientos populares.

Las búsquedas realizadas en estos dos contextos urbanos también fueron evaluadas positivamente. Un factor ponderado fue la conjunción entre el entorno rural y el constante crecimiento de la zona. Es "campo", dice Laura, pero "la zona seguro va a seguir creciendo" 24 . En este sentido, era frecuente que se sintieran cómodos/as en contextos urbanos donde se identificaban como "pioneros" dispuestos/as a "llegar en banda" y "copar un barrio"25.

Otro factor que les resultó ventajoso fueron las potenciales ganancias de localización en términos de renta (Bourdieu, 2013) que anticipaban en caso de mudarse a la zona norte, como postula Graciela, una beneficiaria del PROCREAR:

Con mi novio buscábamos en la zona norte porque decíamos "lo que construya en la zona oeste no va a valer lo mismo que construya en la zona norte ni lo que construya en la zona sur, y el préstamo para mí va a ser igual", así que decidimos buscar allá. (Comunicación personal, junio 2014).

También era frecuente en esta zona comparar los precios de los lotes ofertados con los lotes cercanos (significativamente más caros) ubicados dentro de la trama urbana, para ponderar la valorización que tendrían luego de su rezonificación y urbanización.

Con todo, las tres ofertas que evaluaron en la zona norte las consideraron como posibles destinos de sus mudanzas. No sucedió lo mismo en la zona sur. Allí visitaron tres predios. Uno de ellos se ubicaba en Altos de San Lorenzo, un barrio cercano al centro de la ciudad, históricamente habitado por sectores populares. El rechazo por esos lotes fue unánime e inmediato. Para Luna, la zona era "horrible", además consideraba que había " $¡$ muchos robos y terrenos tomados!". También para Eva "la zona era fea" y Camila evaluaba que era "peligrosa" 26 .
En la misma zona vieron una oferta ubicada en Villa Elvira, otra delegación de origen popular y con predominancia de población de bajo nivel socioeconómico (Matteucci, 2015). Los terrenos se encontraban a pocas cuadras del centro de la ciudad y contaban con todos los servicios. Sin embargo, ninguno de estos rasgos tuvo peso en su decisión:

Info sobre los de Villa Elvira: las cuatro calles frente al terreno son de casas muy humildes, (..) parece ser de clase media/media baja. Pasan colectivos por la esquina. Los lotes cuentan con: LUZ y AGUA CORRIENTE. El servicio de GAS NATURAL ${ }^{27}$ llega hasta la esquina de la manzana. A ver... comparado con los de Gorina, son una reverenda cagada. (comunicación personal, octubre 31,2013$)$.

El terreno de Gorina tenía peores accesos, menos servicios, estaba alejado del centro y también había en sus inmediaciones hogares de menor nivel socioeconómico. Sin embargo, la diferencia era medular: era una "zona en evolución" y por ello un destino apropiado para "hacer la movida".

Por último, también en la zona sur el grupo visitó predios en Parque Sicardi, delegación que —a diferencia de Villa Elvira y Altos de San Lorenzo- está alejada del centro $^{28}$ y se encuentra entre dos grandes barreras físicas, el Aeródromo Provincial y una localidad rural vecina. Al evaluar esta oferta encontraron dos desventajas: el tamaño de los lotes $\left(300 \mathrm{~m}^{2}\right)$ — "muy chicos en comparación con las casonas que hay" - y tener que "pasar por Villa Elvira para llegar" 29 . Las ventajas eran por un lado estéticas y se vinculaban a la presencia de entornos "verdes". Por el otro, la presencia de "mucho PROCREAR" y "casas nuevas" fungía de resguardo respecto al crecimiento y recomposición social del barrio.

Resumiendo, de las búsquedas realizadas, todas aquellas ubicadas en la zona norte resultaron un destino posible para la construcción de sus viviendas. En la zona sur, en cambio, solo fue evaluada positivamente la oferta de Parque Sicardi. Los predios de Villa Elvira y Altos de San Lorenzo, si bien estaban dentro de su poder de pago,

\footnotetext{
${ }^{24}$ Publicado el 22 de noviembre de 2013 en el muro de Facebook del grupo "22 de octubre".

${ }^{25}$ Estas expresiones — junto a otras de igual sentido - corresponden a publicaciones en el muro de Facebook del grupo "22 de octubre".

${ }^{26}$ Evaluaciones publicadas el 31 de octubre de 2013 en el muro de Facebook del grupo "22 de octubre".

${ }^{27}$ El resaltado es de la fuente.

${ }^{28}$ Se encuentra a $10 \mathrm{~km}$, distancia relevante considerando la escala de la ciudad.

${ }^{29}$ Ambas citas corresponden a publicaciones realizadas el 30 de noviembre de 2013 en el muro de Facebook del grupo "22 de octubre".
} 
contaban con todos los servicios y estaban próximos al centro, les resultaban "feos" y "peligrosos" (tabla 1).

\section{Tabla 1}

Búsqueda de terrenos según zona, localidad y evaluación realizada por beneficiarios/as.

\begin{tabular}{lll}
$\begin{array}{l}\text { Eje de crecimiento } \\
\text { urbano }\end{array}$ & \multicolumn{1}{c}{$\begin{array}{c}\text { Zona donde se } \\
\text { ubicaba la oferta }\end{array}$} & $\begin{array}{c}\text { Evaluación de } \\
\text { beneficiarios/as }\end{array}$ \\
\hline \multirow{2}{*}{ Noroeste } & El Rincón & Positiva \\
\cline { 2 - 3 } & Arturo Seguí & Positiva \\
\hline & Altos de San Lorenzo & Negativa \\
\cline { 2 - 3 } Sureste & Pilla Elvira & Negativa \\
\cline { 2 - 3 } & & \\
\hline
\end{tabular}

Fuente: Elaboración propia con base en trabajo de campo, documentos publicados en el muro de Facebook del GULP

Como vemos, al interior de un mismo segmento de mercado, no toda periferia les daba lo mismo y por ello la "Vía 2" era fundamental. En este punto es importante señalar que los criterios de este pequeño subgrupo de beneficiarios/as es representativo, siendo sus preferencias similares a las de otros grupos que aplicaron a la "Vía 2", ubicándose la mayoría de los loteos en las delegaciones ${ }^{30}$ de Parque Sicardi y Arturo Seguí ${ }^{31}$ (figura 2).

A continuación, presentaremos una breve descripción de la estructura urbana platense, así como de la dinámica de crecimiento de las distintas zonas de la ciudad, a fin de reponer el arraigo urbano de los esquemas de preferencia de beneficiarios/as, y la contribución de dichas decisiones - aparentemente descoordinadas - en la reproducción de la segmentación espacial.

\section{Los esquemas de preferencia a la luz de la dinámica urbana}

La Plata es una ciudad com-fusa (Abramo, 2012) con un casco fundacional densificado - aloja el 37,7\% de

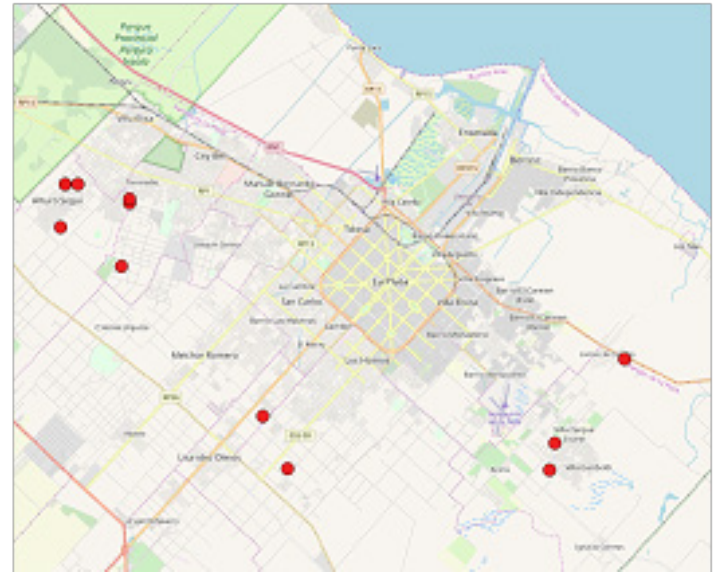

Figura 2. Ubicación de los barrios generados por la "Vía 2" de la ordenanza N 11.094/13. Fuente: elaboración propia con base en el Open Street Maps.

la población en el 3,2\% de la superficie-, y periferias que se expandieron abarcando el $96,7 \%$ de la superficie urbana, donde reside el $62,3 \%$ de los/as habitantes (Cortizo, 2020). Los ejes de expansión son tres y, además de ser de baja densidad, se encuentran desfasados con avance de los servicios básicos y la infraestructura (Cortizo, 2020) (figura 3).

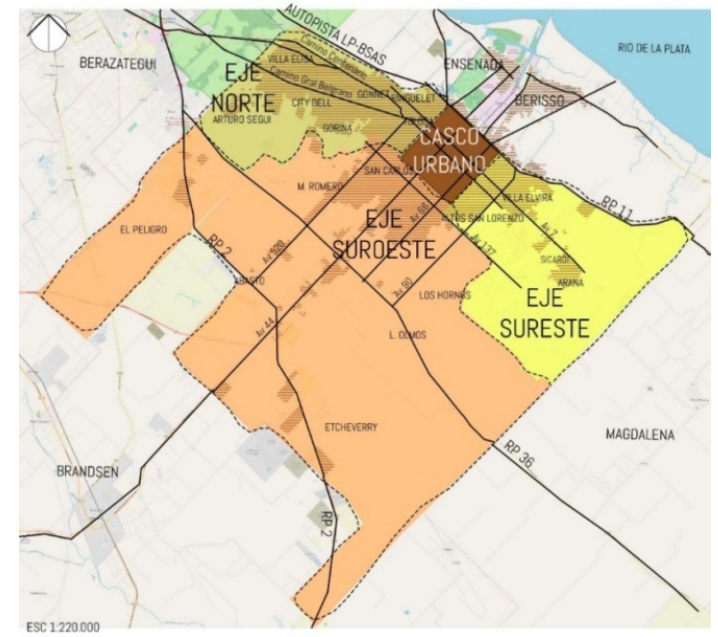

Figura 3. Áreas de crecimiento urbano de La Plata. Fuente: Cortizo (2020).

Asimismo, cada uno de ellos contiene distintos contextos urbanos (Duhau \& Giglia, 2004). Al analizar las dinámicas de aquellos ejes elegidos por este subgrupo de beneficiarios/

\footnotetext{
${ }^{30}$ Las delegaciones son espacios de descentralización administrativa al interior de los municipios argentinos.

${ }^{31}$ Mediante esta "Vía" se generaron también dos loteos en el eje suroeste. Uno de ellos — llamado el "Gigante del Oeste" — cuenta con varias particularidades que exigen un tratamiento diferencial, por lo que quedó por fuera de nuestra investigación.
} 
as —donde a su vez se anclaron la mayoría de los loteos generados por la "Vía 2"- encontramos que el eje norte aloja a la población de mayor poder adquisitivo y cuenta con dos grandes periferias. Por un lado, zonas cercanas al casco de la ciudad con un alto grado de consolidación y tejido compacto de baja densidad. Por otro, una con menor grado de consolidación y tejido disperso (Cortizo, 2020), donde tienden a residir las nuevas generaciones de los sectores medios asentados en las zonas consolidadas del eje norte (Matteucci, 2015).

El eje sureste contiene una primera periferia ubicada en las inmediaciones del centro de la ciudad - integrada por Villa Elvira y Altos de San Lorenzo - caracterizada por un alto grado de consolidación urbana. En su interior hay zonas de urbanización más reciente, caracterizadas por mayores déficits de infraestructura, población de bajos ingresos y un alto porcentaje de asentamientos informales (Cortizo, 2020).

Una segunda periferia del eje sureste se caracteriza por el uso residencial de baja densidad. En ella se ubican las delegaciones Arana y Parque Sicardi. Esta última sufrió en las últimas dos décadas un fuerte cambio en su morfología, pasando del predominio de casas quintas y usos rurales a la conformación de viviendas permanentes. A pesar de la falta de servicios e infraestructuras básicas y su lejanía respecto al casco urbano, tuvo en los últimos años un crecimiento exponencial protagonizado por los sectores medios (Matteucci, 2015).

De todas las ofertas que recorrieron los/as beneficiarios/ as, aquellas ubicadas en la zona norte pertenecen a la subperiferia que cuenta con un bajo grado de consolidación y tejido disperso. En cuanto a la zona sureste, las ofertas de Altos de San Lorenzo y Villa Elvira pertenecen a la periferia consolidada, mientras que Parque Sicardi a aquella otra periferia de baja consolidación y densidad.

Respecto al nivel socioeconómico ${ }^{32}$, al considerar los contextos urbanos específicos que recorrieron y evaluaron beneficiarios $/ \mathrm{as}^{33}$, reconstruimos que el predio ubicado en Gorina se encontraba en una intersección con fuerte contraste social. La delegación, por su parte, se caracteriza por un nivel socioeconómico medio-bajo (Matteucci, 2015). El predio de Arturo Seguí era lindante a viviendas precarias aisladas, mientras que en la delegación coexisten sectores bajos y medios-altos (Matteucci, 2015), también con marcado contraste social. La oferta del barrio El Rincón se encuentra en la delegación City Bell, caracterizada por un nivel socioeconómico alto y medio-alto, con baja presencia de sectores medios-bajos. En la observación de campo encontramos una predominancia de sectores medios en los predios linderos a la oferta. Por su parte, en los loteos de la zona sur tanto las delegaciones Altos de San Lorenzo como Villa Elvira alojan a población de nivel socioeconómico bajo y medio-bajo. Lo mismo opera para los entornos de las ofertas evaluadas por beneficiarios/as. En el caso de Parque Sicardi, tanto la delegación como los predios se caracterizaban por la presencia de sectores medios, con una marcada homogeneidad social.

En relación a la antigüedad de los contextos urbanos donde se encuentran las ofertas analizadas, Parque Sicardi, Arturo Seguí, El Rincón y Gorina pertenecen a zonas "jóvenes" (2001-2011) y con una dinámica de crecimiento demográfico acelerado. Son zonas que, pese a sus atributos de partida, se encuentran experimentando fuertes cambios en términos de su perfil urbano. Mientras tanto, las ofertas analizadas en Altos de San Lorenzo y Villa Elvira son áreas de crecimiento estable o leve. Este punto es medular en tanto ratifica su tendencia como "territorio popular" ya que la aceleración del crecimiento demográfico no podría estar contribuyendo a redefinir la composición social del vecindario.

Finalmente, interesa considerar la valorización del precio del suelo de dichas áreas. Cortizo (2020) encuentra, entre 2010 y 2018, una diferencia en la valorización relativa del suelo de áreas suburbanas consolidadas y áreas “jóvenes", recientemente colonizadas por sectores medios: Arturo Seguí se valorizó 376\%, Arana 259\% (caso similar y lindero a Parque Sicardi) y Gorina 247\%. Mientras tanto, periferias consolidadas y poco dinámicas se valorizaron considerablemente menos: Villa Elvira 78\%, Gonnet 95\% y City Bell 116\% (tabla 2).

En síntesis, los datos arrojan que las tendencias de cambio observadas en la estructura urbana y el reconocimiento de

\footnotetext{
${ }^{32}$ Para caracterizar a las delegaciones según el nivel socioeconómico de su población, se considera el porcentaje de población con Necesidades Básicas Insatisfechas (Censo 2010). Ello se complementa con la caracterización de los predios particulares ofertados, realizadas mediante las notas de campo.

${ }^{33}$ Es decir, en este punto no solo consideramos las características de las delegaciones en las que se inscribieron, sino también de los entornos inmediatos a los predios.
} 


\section{Tabla 2}

Análisis de la tierra ofertada en base al perfil urbano de las zonas

\begin{tabular}{|c|c|c|c|c|c|c|}
\hline & \multicolumn{3}{|c|}{ Eje norte } & \multicolumn{3}{|c|}{ Eje sureste } \\
\hline Delegación & Gorina & El Rincón & Arturo Seguí & $\begin{array}{l}\text { Altos de San } \\
\text { Lorenzo }\end{array}$ & Villa Elvira & $\begin{array}{l}\text { Parque } \\
\text { Sicardi }\end{array}$ \\
\hline $\begin{array}{l}\text { Evaluación de } \\
\text { beneficiarios/as }\end{array}$ & Positiva & Positiva & Positiva & Negativa & Negativa & Positiva \\
\hline $\begin{array}{l}\text { Nivel socioeconómico } \\
\text { predominante }\end{array}$ & $\begin{array}{l}\text { Medio-bajo y } \\
\text { Medio-alto }\end{array}$ & Medio & Medio-bajo & Bajo & Bajo & Medio \\
\hline Consolidación urbana & Media & Baja & Baja & Alta & Alta & Baja \\
\hline Valorización inmobiliaria & Alta & Media & Alta & Media & Baja & Alta \\
\hline $\begin{array}{l}\text { Crecimiento } \\
\text { demográfico }\end{array}$ & $\begin{array}{l}\text { Moderado a } \\
\text { Acelerado }\end{array}$ & Acelerado & Acelerado & $\begin{array}{l}\text { Leve a } \\
\text { Moderado }\end{array}$ & $\begin{array}{l}\text { Leve a } \\
\text { Moderado }\end{array}$ & Acelerado \\
\hline $\begin{array}{l}\text { Aceleración del proceso } \\
\text { de suburbanización }\end{array}$ & $1990-2000$ & $2000-2010$ & $1990-2000$ & $1970-1990$ & $1970-2000$ & $2000-2010$ \\
\hline
\end{tabular}

Fuente: elaboración propia con base en la ubicación de la oferta de terrenos y trabajos de Cortizo (2020); Del Río y González (2014); Matteucci (2015); Relli (2019) .

las trayectorias de cada contexto urbano fueron variables estratégicas en las apuestas residenciales de beneficiarios/as.

\section{Discusión}

Como evidenciamos en el apartado anterior, tensionados/ as entre (1) la oportunidad residencial (Di Virgilio, 2007) que implicó el PROCRAR - disruptiva en la trayectoria de la política habitacional argentina y percibida como "única" por sus beneficiarios/as (Segura \& Cosacov, 2019) — y (2) los limites estructurales que les impuso un mercado de suelo desregulado, los/as beneficiarios/ as del PROCREAR buscaron (y lograron) dar lugar a sus expectativas modelando la normativa urbana. En particular pujaron por la sanción de una ordenanza ( $\left.\mathrm{N}^{\circ} 11.094 / 13\right)$ que habilitó el cambio de uso de suelo de rural a urbano y una modalidad especifica de implementación conocida nativamente como "Vía 2".Vimos también que esta estrategia colectiva se basó en tres pilares: A) limitar la intervencián estatal; B) poder incidir en la composicion del loteo, es decir, en quienes serían sus futuros/as vecinos/as; y finalmente $\mathbf{C}$ ) incidir en la localizacion de los predios.
A) El objetivo de que "el Estado intervenga, pero hasta ahí" se basó en dos aspectos. El primero de ellos se vincula al poder de pago que podía movilizar la población beneficiaria del PROCREAR, el cual — suponían — les permitiría acceder a suelo de mayor calidad. Legitimando al mercado como el mejor asignador de recursos, la "Vía 2" - y con ella la implementación del PORCREAR en la capital de la Provincia de Buenos Aires- se estructuró alrededor de una noción patrimonialista de ciudadanía (Svampa, 2005). En la Argentina, como producto de la mercantilización de los bienes básicos que se dio en los años noventa, se expandió este tipo de ciudadanía sustentada en la idea del ciudadano como propietario y en la autorregulación como base de la autonomía individual. En términos territoriales, ello se expresó en el crecimiento de las urbanizaciones cerradas, las cuales —además de la socialización entre iguales y la separación de los estratos sociales más bajos mediante barreras físicas - exigían cierta independencia del Estado (Svampa, 2005). Estos dos pilares de la ciudadanía patrimonialista operaron en la disputa de los/as beneficiarios/as en búsqueda de la "Vía 2": por un lado, buscaron la autorregulación de la composición del vecindario y de la localización y 
urbanización de los predios - volveremos sobre esto más adelante - como base de la autonomía individual. Por otro, se posicionaron distinguiendo los derechos comunes a todos/as los/as ciudadanos/as de los derechos particulares adquiridos por la vía del mercado.

El segundo motivo por el cual los/as beneficiarios/as buscaron limitar la intervención estatal fue para evitar que este les asigne "cualquier" posición devaluada en la estructura urbana, es decir, una posición en la que ellos/ as no pudieran elegir las variables de dicha devaluación ni la composición del vecindario. Dieron cuenta con ello de la interiorización de una norma que rige el espacio social reificado ${ }^{34}$, por la cual la localización aparece como un rango de posición vinculado con el espacio social, lo que deriva en que determinados lugares correspondan tácitamente a determinadas personas (Bourdieu, 2013). Así, en sus imaginarios, el espacio urbano del que el Estado dispone para la política habitacional no correspondía a su estatus social; y por ello, que fuera el Estado quien les asignara una localización en la ciudad resultaba pertinente. En este tipo de acciones cotidianas desplegadas en relación al hábitat urbano y el habitar, se da un proceso de ciudadanización (Garibotti, Girola \& Boroccioni, 2017; Girola, 2017) en el que — en futuros trabajos - tendremos que profundizar. Tal como afirma Ramírez Kuri (2007), las ciudades contemporáneas se han convertido en los escenarios privilegiados en los que se dirime el lugar que una persona o un grupo ocupan en la sociedad y el Estado.

B) El segundo componente que estructuró la estrategia residencial colectiva de los/as beneficiarios/as fue la disputa por incidir en la composición de los futuros barrios, lo cual fungía como un amparo frente a una decisión residencial que implicaba la suburbanización de personas que hasta ese momento residían — en su mayoría - en el centro de la ciudad. El cambio en la posición residencial implicaba atravesar sus propias fronteras territoriales y redefinir disposiciones espaciales, de allí que la afinidad social se volviera crucial.

Este factor tuvo a su vez dos dinámicas. Una de ellas se vinculó a la productividad de las interacciones que las mudanzas conjuntas y "entre iguales" habilitaba y la capitalización es de ellas pudiera surgir. En concreto, encontramos que los/as beneficiarios/as colectivizaron su capital social y cultural haciendo más fácil, ágil y económico todo el proceso. A su vez se generaron expectativas futuras respecto a que la proximidad en el espacio físico potenció la productividad del capital social, "posibilitando el aprovechamiento constante de los encuentros a la vez fortuitos y previsibles que asegura la frecuentación de lugares bien frecuentados" (Bourdieu, 2013, p. 121). Respecto al último punto, analizando las clases medias chilenas, Barozet (2006) detectó que más que su capital económico, lo que estas ponen en juego en el mantenimiento de su lugar en la estructura social es una "manifestación extremadamente eficiente del capital social" (p. 70). Lo mismo operó en el caso de los/as beneficiarios/ as del PROCREAR, quienes en gran medida lograron (y buscaron) modelar la normativa urbana mediante (y en búsqueda) de la colectivización de sus jerarquizadas redes de contactos.

En otro orden, la autogestión en la composición del vecindario tuvo componentes afectivos vinculados a las expectativas en torno formas de habitar los futuros barrios y al retorno a una dinámica barrial idealizada. En este punto, la "Vía 2" amortiguaba un sistemático descuido de la política habitacional argentina: la reducción del problema habitacional a la construcción de casas y la subestimación de los entornos barriales.

En síntesis, la optimización - productiva y afectivade las externalidades de vecindad (Abramo, 2009) fue fundamental en sus movimientos y estrategias residenciales. Ello fue, por un lado, una forma de proyectar lazos de solidaridad frente a la incertidumbre que les generaba mudarse a las afueras de la ciudad, un amparo frente a zonas que - a priori- les resultaban hostiles. Por el otro, las externalidades de vecindad habilitadas por las mudanzas conjuntas entre iguales y la capitalización de las interacciones por ellas promovidas, facilitaran la reproducción de la clase social, de personas que se auto adscribían como clases medias y que en sus inminente suburbanización se exponían a la devaluación de su capital locacional.

En este punto nos interesa reparar en el contrapunto que se da respecto a la relación "composición del vecindariovivienda social" cuando la población objetivo son los sectores populares. Al detenerse en la sociabilidad al interior de los barrios generados por el PFCV - un programa de vivienda destinado a los sectores populares argentinos - , Del Río (2012) encontró que la conformación del vecindario estuvo marcada por la incomodidad asociada a la desconfianza mutua. La mudanza masiva, simultánea y no mediada por redes sociales previas, explicó en parte

\footnotetext{
${ }^{34}$ Con este término Bourdieu (2013) refiere a la materialización de la estructura social en el espacio.
} 
este sentimiento. En nuestro caso también se produjeron mudanzas conjuntas entre personas que no se conocían entre sí, sin embargo, aquí la clase social operó como una garantía para la socialización, jugando un papel clave el efecto de socialización. En este sentido, desde sus imaginarios los barrios podían no ser los mejores, pero los/as vecinos/as sí lo eran. Queremos enfatizar en este punto que, en la relación entre trayectoria residencial y vecindario, la "Vía 2" configura un reposicionamiento residencial inverso al observado con mayor frecuencia en las mudanzas de los sectores populares a los barrios de vivienda social, donde el imaginario más extendido es: buenos barrios, malos vecinos (Del Rio, 2012).

C) Finalmente, en una segunda parte del artículo mostramos cómo la puja por la incorporación de la "Vía 2" a la ordenanza $\mathrm{N}^{\circ} 11.094 / 13$ se motorizó por las expectativas de incidir en la localizacion de los predios por ella rezonificados. La biblografía muestra que la estructura urbana y las biografías de los hogares se modifican mutuamente y, en parte por ello, las elecciones de localización son decisiones cruciales que se dan en contextos de incertidumbre radical (Abramo, 2009). A su vez, la descentralización de las elecciones de localización hace que, además de intertemporales, sean interdependientes, poniéndose en juego las especulaciones de los hogares en torno a la evolución de las distintas zonas y las decisiones que tomarán otros actores. Conforme Abramo (2009), dentro de estos actores el capital inmobiliario tiene una capacidad diferencial para modelar las preferencias de los/as consumidores/as y generar zonas que alojen a (y por tanto sean elegidas) familias del mismo tipo. De ese modo, el mercado logra constituir una configuración espacial en parte influyendo sobre las expectativas cruzadas nacidas de contextos cognitivos similares.

De lo anterior, se desprende que la emergencia del orden residencial es coordinada por el mercado y reproducida por los hogares, teniendo una fuerte dimensión subjetivacognitiva (Abramo, 2009). Al acompañar las búsquedas de lotes realizadas por un subgrupo de beneficiarios/as encontramos que al momento de la territorialización de la "Vía 2", buscaron inscribirse en determinados contextos urbanos (Duhau \& Giglia, 2004). En particular, la "Vía 2" les permitió - dentro de las restricciones estructurales impuestas por el mercado - priorizar aquellas periferias que, si bien se encontraban alejadas de la ciudad y con bajos niveles de consolidación urbana, presentaban una dinámica de crecimiento específica: periferias "jóvenes”, con acelerado crecimiento demográfico, predominancia progresiva de población de sectores medios y alta valorización inmobiliaria. Contrariamente, descartaron de manera unánime - a pesar de su cercanía al centro y consolidación urbana - zonas donde predominaba población de bajo nivel socioeconómico, con antigüedad del tejido y una valorización moderada o baja durante las últimas décadas.

Como vemos, independientemente del grado de consolidación urbana, el factor que definió sus decisiones de localización fue la tendencia de cambio de las distintas zonas; es decir la dinámica de crecimiento y valorización inmobiliaria se impuso sobre "la foto" de la ciudad al momento de realizar las búsquedas de predios. De este modo, los esquemas de preferencia de los/as beneficiarios/ as fueron performados por la estructura urbana y su dinámica, a la vez que dichos esquemas de preferencia modelaron la forma en que se implementó localmente el PROCREAR y, con ello, la producción de ciudad. Así, se pone en evidencia la recursividad entre la reproducción de la clase social y el espacio urbano.

\section{Conclusiones}

A lo largo de este artículo reconstruimos la disputa que llevaron adelante los/as beneficiarios/as del PROCREAR en torno a la inclusión o exclusión de la "Vía 2" a la ordenanza $\mathrm{N}^{\circ} 11.094 / 13$. Nuestro objetivo fue analizar cómo integrantes de las clases medias maniobraron frente a la tensión que se dio entre la oportunidad residencial que les brindó el Estado (PROCREAR) y el lugar en la ciudad que les asignó el mercado de suelo. A su vez, mediante el acompañamiento a un subgrupo de beneficiarios/as en la búsqueda de posibles predios donde generar sus futuros barrios, mostramos la forma en que esas maniobras se territorializaron en la ciudad.

Respecto al caso concluimos que los argumentos y expectativas que estuvieron detrás de la "Vía 2", así como su territorialización y la respuesta estatal frente a ello, fueron un proceso de diferenciación social y espacial en al cual los/as beneficiarios/as produjeron activa y conjuntamente su posición en el espacio social. Una operación de acercamiento social y alejamiento físico, en la cual integrantes de las clases medias buscaron resguardar su posición en el espacio social mediante la generación de barrios ubicados en determinados contextos urbanos alejados de la centralidad, pero con dinámicas de crecimiento específicas. Barrios en los que pudieran, además, autogestionar la composición del vecindario garantizando cohabitar con determinado "tipo de gente". Dicho de otro modo, ante su inminente pérdida de capital locacional, 
los/as beneficiarios/as gestionaron cercanías y lejanías sociales y espaciales; $y$, en ese sentido, buscando reproducir/ resguardad la clase contribuyeron a la reproducción de un modo segmentado de producir y consumir ciudad.

Independientemente del caso, buscamos promover la reflexión sobre la productividad social y urbana de las prácticas sociales que individuos y colectivos pertenecientes a las clases medias despliegan para producir ciudad y su propia inscripción en ella. Un hacer urbano poco estudiado y que, tal como señala Cosacov $(2014,2017)$, no solo informa sobre el anclaje territorial de un sector, sino sobre el funcionamiento de todo el orden urbano. Un orden urbano que es resultado de actores con desiguales capacidades de incidir en su estructuración, siendo las clases medias uno de esos actores.

\section{Agradecimientos}

Este artículo forma parte de una investigación doctoral financiada por el Consejo Nacional de Investigaciones Científicas y Técnicas (CONICET). Dicha investigación fue posible también gracias al Centro de Investigaciones Geográficas (Facultad de Humanidades y Ciencias de la Educación, Universidad Nacional de La Plata), el cual aportó el lugar de trabajo. Por último, el artículo se enmarca en el Proyecto $\mathrm{I}+\mathrm{D}+\mathrm{i}$ "Producción Social del Hábitat en áreas metropolitanas del Norte y el Sur Global: políticas, instituciones y movilización social (ALTERHABITAT)" Ref.: (PID2019-105205RB-100), AEI:10.130.139/501100011033, financiado por el Ministerio de Ciencia, Innovación y Universidades (España).

\section{Referencias}

Abramo, P. (2003). La teoría económica de la favela: cuatro notas sobre la localización residencial de los pobres y el mercado inmobiliario informal. Revista Ciudad y territorio: Estudios territoriales, 35(136137), 273-294. Recuperado de https://recyt.fecyt.es/ index.php/CyTET/article/view/75391

Abramo, P. (2009). La ciudad calidoscópica. Revista Apuntes de Cenes, 28(48), 125-196. Recuperado de https://dialnet.unirioja.es/descarga/articulo/3399342.pdf

Abramo, P. (2012). La ciudad com-fusa: mercado y producción de la estructura urbana en las grandes metrópolis latinoamericanas. EURE, 38(114), 35-69. https://doi.org/10.4067/s0250-71612012000200002
Adamovsky, E. (2013). "Clase media": reflexiones sobre los (malos) usos académicos de una categoría. Revista Nueva Sociedad, 247, 38-49. Recuperado de https://nuso.org/media/articles/downloads/3976_1.pdf

Barenboim, C. A. (2019). Políticas habitacionales y de suelo en la ciudad de Rosario, Argentina. Revista de Direito da Cidade , 11(1), 469-484. https://doi. org/10.12957/rdc.2019.36090

Barozet, E. (2006). El valor histórico del pituto: clase media, integración y diferenciación social en Chile. Revista de Sociología, 20, 69-96. http://dx.doi. org/10.5354/0719-529X.2006.27531

Bourdieu, P. (2013). La miseria del mundo. Buenos Aires: Fondo de Cultura Económica.

Carrión Mena, F. \& Núñez-Vega, J. (2006). La inseguridad en la ciudad: hacia una comprensión de la producción social del miedo. EURE, 32(97), 7-16. http://dx.doi.org/10.4067/S0250-71612006000300001.

Cefaï, D. (2012). ¿Qué es una arena pública? Algunas pautas para un acercamiento pragmático. En Daniel Cefaï \& Isaac Joseph (Eds.), L'heritage du pragmatisme. Conflitsd'urbanité et épreuvesdecivisme (pp. 51-81). La Tour d'Aigues: Éditions de l'Aube.

Cortizo, D. (2020). Tierra vacante: Estado y mercado en los procesos de crecimiento urbano. Oportunidades y desafíos para su gestión en el Partido de La Plata (Tesis de Doctorado). Facultad de Humanidades y Ciencias de la Educación, Universidad Nacional de la Plata, La Plata, Argentina. Recuperado de http://www.memoria. fahce.unlp.edu.ar/library? $\mathrm{a}=\mathrm{d} \& \mathrm{c}=$ tesis\&d=Jte1831

Cosacov, N. (2014). Habitar la centralidad. Trayectorias residenciales y usos cotidianos del espacio urbano de residentes en Caballito, Buenos Aires (Tesis de Doctorado). Facultad de Ciencias sociales, Universidad de Buenos Aires, Buenos Aires, Argentina.

Cosacov, N. (2017). Construyendo un barrio de clase media. Narrativas, moralidades e identidades de clase media en disputas urbanas. En Martín Boy \& Mariano Perelman (eds.), Fronteras en la ciudad. (Re) producción de desigualdades y conflictos urbanos (pp. 95-128). Buenos Aires: Editorial Teseo. 
Cosacov, N., Di Virgilio, M. M. \& Najman, M. (2018). Movilidad residencial de sectores medios y populares: la ciudad de Buenos Aires como punto de llegada. Revista Cadernos Metrópole, 20 (41), 99-121.http:// dx.doi.org/10.1590/2236-9996.2018-4105

Cravino, M. C., Fernández Wagner, R. \& Varela, O. (2002). Notas sobre la política habitacional en el AMBA en los años 90. En Luciano Andrenacci (organizador), Cuestión social y política social en el Gran Buenos Aires (pp. 107-124). La Plata: Ediciones Al Margen y Ediciones UNGS.

Delaunay, D. \& Dureau, F. (2004). Componentes sociales y espaciales de la movilidad residencial en Bogotá. Revista Estudios Demográficos y Urbanos, 55, 77-113. Recuperado de http://www.redalyc.org/ articulo.oa? $\mathrm{id}=31205502$

Del Río, J. (2012). El lugar de la vivienda social en la ciudad: Un análisis de la política habitacional desde el mercado de localizaciones intraurbanas y las trayectorias residenciales de los habitantes (Tesis de Doctorado). Facultad de Humanidades y Ciencias de la Educación, Universidad Nacional de la Plata, La Plata, Argentina. Recuperada de http://www.memoria. fahce.unlp.edu.ar/art_revistas/pr.5497/pr.5497.pdf

Del Río, J. (2017). Crédito hipotecario, acceso al suelo y clase media en la implementación del Pro.Cre.Ar en la ciudad de La Plata. En María Cristina Cravino (ed.), Detrás de los conflictos. Estudios sobre la desigualdad urbana en la Región Metropolitana de Buenos Aires (pp. 265-305). Los Polvorines: Ediciones UNGS.

Del Río, J. \& González, P. (septiembre, 2014). Estructura urbana y precios del suelo. Reflexiones metodológicas para su estudio en el Gran La Plata. Trabajo presentado en X Bienal del Coloquio de Transformaciones Territoriales AUGM. Córdoba, Argentina.

Di Virgilio, M. (2007). Trayectorias residenciales y estrategias habitacionales en sectores populares $\mathrm{y}$ medios en Buenos Aires (Tesis para Doctorado). Facultad de Ciencias sociales, Universidad de Buenos Aires. Buenos Aires, Argentina.

Di Virgilio, M. \& Heredia, M. (2012). Presentación Dossier "Clase social y territorio". Revista Quid 16 , 2, 4-19. Recuperado de http://biblioteca.clacso.edu.ar/
Argentina/iigg-uba/20140626033526/Quid-16-no-2.pdf

Duhau, E. (2003). División social del espacio metropolitano y movilidad residencial. Papeles de población, 9 (36), 161-210. Recuperado de http://www.scielo.org. $\mathrm{mx} /$ scielo.php?script=sci_ arttext\&pid=S1405-74252003000200008

Duhau, E. \& Giglia, A. (2004). Conflictos por el espacio y orden urbano. Estudios Demográficos y Urbanos, 56, 257-288. Recuperado de https://www.redalyc.org/ pdf/312/31205601.pdf

Fava, R. (2014). La clase media, entre la historia y la cultura. Representaciones sociales sobre los "vecinos" en el conflicto con los "ocupantes" durante la toma del Parque Indoamericano. En María Cristina Cravino (ed.), Derecho a la ciudad y conflictos urbanos. La ocupación del Parque Indoamericano (pp. 85-111). Los Polvorines: Ediciones UNGS.

Garguin, E. (2006). La formación histórica de la clase media en Argentina. Una aproximación bibliográfica. Apuntes de Investigación del CECYP, 11, 228-239.

Garibotti, M. B., Girola, M. F. \&Boroccioni, L. (2017). Ciudadanía y hábitat en la ciudad de Buenos Aires desde una perspectiva etnográfica. Vivienda \& Ciudad, 4. 12-26. Recuperado de https://revistas.unc. edu.ar/index.php/ReViyCi/article/view/19008

Girola, M. F. (2017). De la ciudadanía universal a la(s) ciudadanía(s) local(es). Inmediaciones de la comunicación, 12(1), 155-177. https://doi. org/10.18861/ic.2017.12.1.2671

Hine, C. (2004). Etnografía virtual. Barcelona: Editorial UOC.

Jaramillo, S. (2008). Reflexiones sobre la "informalidad" fundiaria como peculiaridad de los mercados del suelo en las ciudades de América Latina. Territorios, 18-19 11-53. Recuperado de https://revistas.urosario. edu.co/index.php/territorios/article/view/826

Kessler, G. \& Di Virgilio, M. (2008). La nueva pobreza urbana: dinámica global, regional y argentina en las últimas dos décadas. Revista de la CEPAL, 95, 31-50. Recuperado de https://repositorio.cepal.org/bitstream/ handle/11362/11250/1/095031050_es.pdf 
Lévy, J. (1998). Habitat et habitants: position et mobilité dans l'espace résidentiel. En Grafmeyer, Y. y Dansereau, F., Trajectoires familiales et espaces de vie en milieu urban. Lyon, Presses universitaires de Lyon.

Matteucci, L. (2015). Dime cuánto vale y te diré quién vive: Análisis de la relación entre los precios del suelo y el nivel socio-económico de los hogares en el partido de La Plata entre 2001 y 2010 (Tesis de Pregrado). Facultad de Humanidades y Ciencias de la Educación, Universidad Nacional de la Plata. La Plata, Argentina. Recuperado de http://www.memoria. fahce.unlp.edu.ar/library? $\mathrm{a}=\mathrm{d} \& \mathrm{c}=$ tesis \&d=Jte1219

Melé, P. (2016). ¿Qué producen los conflictos urbanos? En Fernando Carrión (ed.), El derecho a la ciudad en América Latina. Visiones desde la política (pp. 127155). México: UNAM, PUEC, CIALC, IDRC/CRDI.

Minujin, A. (1992). Cuesta abajo. Los nuevos pobres: efectos de la crisis en la sociedad argentina. Buenos Aires: UNICEF-Losada.

Mosquera Villegas, M. A. (2008). De la Etnografía antropológica a la Etnografía virtual. Estudio de las relaciones sociales mediadas por Internet. Fermentum, 18(53), 532-549. Recuperado de https:// www.redalyc.org/pdf/705/70517572006.pdf

Olson, M. (1992). La lógica de la acción colectiva, bienes públicos y la teoría de grupos. Departamento de Economía de la Universidad de Harvard. Limusa Noriega Editores. México D.F

Relli, M. (2019). Desencuentros entre política urbana y política de regularización del hábitat popular en La Plata, Argentina. Anales De Geografía De La Universidad Complutense, 39(2), 439-462. https:// doi.org/10.5209/aguc.66946

Ramírez Kuri, P. (2007). La ciudad, espacio de construcción de ciudadanía. Revista Enfoques: Ciencia Política y Administración Pública, 7, 85-107.

Ramírez, L. (2016). Movilidad residencial y trayectorias habitacionales: Un análisis teóricometodológico de estudios realizados en el área metropolitana de Buenos Aires (Tesis de Pregrado). Facultad de Humanidades y Ciencias de la Educación, Universidad Nacional de La Plata,
La Plata, Argentina. Recuperado de http://www. memoria.fahce.unlp.edu.ar/tesis/te.1196/te.1196.pdf.

Rodríguez, M. F. (2013). Las formas "pobres” de hacer ciudad: un recorrido histórico sobre las modalidades de hábitat popular y su incidencia en la agenda estatal. Revista del CCC , 13. Recuperado de https:// www.centrocultural.coop/revista/13/las-formas-pobresde-hacer-ciudad-un-recorrido-historico-sobre-lasmodalidades-de-habitat

Schteingart, M. (2001). Los productores del espacio habitable: Estado, empresa y

sociedad en la Ciudad de México. México: El Colegio de México.

Smolka, M. (1992). Mobilidadeintra-urbana no Rio de Janeiro: da estratifição social a segregação residencial no espaço. Revista Brasileira de Estudos de População, 9(2), 97-114. Recuperado de https:// www.rebep.org.br/revista/article/view/502

Segura, R. (2015). Vivir afuera. Antropología de la experiencia urbana. San Martín: UNSAM Edita.

Segura, R. \& Cosacov, N. (2019). Políticas públicas de vivienda: impactos y limitaciones del Programa Procrear. Ciencia, tecnología y política, 2(2), 1-15. https://oi.org/10.24215/26183188e018

Svampa, M. (2005). La sociedad excluyente. La Argentina bajo el signo del neoliberalismo. Buenos Aires: Taurus.

Ventura, V. (2020). Clases medias y producción de ciudad: un análisis de la implementación del PROCREAR en La Plata (2013-2015) desde las prácticas de su población beneficiaria (Tesis de Doctorado). Universidad Nacional de General Sarmiento. Polvorines, Argentina.

Welschinger Lascano, N. (2012). La etnografía virtual revisitada: Internet y las nuevas tecnologías digitales como objetos de estudio. Revista Latinoamericana de Metodología de las Ciencias Sociales, 2(2), 109-116. Recuperado de http://sedici.unlp.edu.ar/ handle/10915/26949 